Esta obra está sob o direito de Licença Creative Commons Atribuição 4.0 Internacional.

\title{
AUTISTA NA EDUCAÇÃO INFANTIL. A INCLUSAO DE ALUNOS COM AUTISMO NA EDUCAÇAO INFANTIL: DESAFIOS E PRÁTICAS.
}

\author{
Iriscleite da Silva França ${ }^{2}$ \\ Elisângela Oliveira Tavares ${ }^{3}$ \\ Lucília Maria da Silva Soares Barbosa ${ }^{4}$ \\ Ivaci Bonfim Pinheiro
}

\begin{abstract}
RESUMO
O autismo é um distúrbio do desenvolvimento que acompanha o indivíduo durante toda a vida. Podem ser observados no início da infância seus sintomas estão associados a comunicação. As pessoas que interagem com uma criança autista são necessárias que tenha uma abordagem adequada e eficiente, para que a criança consigo desenvolver durante sua vida escolar e social. A escola inclusiva é um importante fator para o relacionamento social e desenvolvimento das habilidades de todos os educandos, esse trabalho tem como objetivo de compreender a inclusão dos alunos autista na educação infantil, utilizando a metodologia com estudo bibliográfico. $\mathrm{O}$ papel do professor é procurar promover a interação do aluno autista com as colegas de classe, transformando suas necessidades em igualdades, também a participação da família eu atua como um suporte para que haja um bom desenvolvimento escolar.
\end{abstract}

Palavra-chave: escola inclusiva - educação infantil - igualdade- família

\footnotetext{
2 iriscleite@gmail.com

3 ely_tavares@hotmail.com

4 luciliaglp@bol.com.br

5 ivaci18@outlook.com
} 


\section{INTRODUÇÃO}

A inclusão é muito importante para o processo do aluno autista na escola e suas atribuições, no ensino inclusivo é um direito conquistada e é dever aceitar e respeitar as diferenças. A realidade no processo inclusivo no contexto do autismo identificando-se as principais dificuldades apresentadas para a inclusão dos alunos autistas considera-se de suma importância a relação família e escola para a inclusão dos alunos autistas.

A escolha desse tema se distingue pela necessidade de novos conhecimentos e informações sobre o autismo. Este trabalho tem como objetivo compreender a inclusão escolar na educação infantil, identificando praticas pedagógicas que facilitam a inclusão escolar das crianças autistas. A formação de professores necessita cada vez mais de novos conhecimentos para que esses possam trabalhar de maneira adequada e desenvolver um ensino de qualidade para esses alunos autistas.

Neste trabalho aborda alguns teóricos e suas ideias, levando a conhecer sobre o autismo.

Bender (1947), utilizou o termo esquizofrenia infantil, pois tanto ele como outros pesquisadores consideravam $\mathrm{o}$ autismo como forma precoce da esquizofrenia, discordando assim, do que kanner propunha salle (2003).

Em 1948 kanner escreveu em seu manual de psiquiatria infantil. Que a maioria das crianças que chegavam até ele com essas características tinha algumas coisas em comum, os pais ou avós eram, na maioria das vezes, médicos, escritores, jornalistas, cientistas e estudiosos que apresentam uma inteligência acima da média e que também apresentavam certa opressão no ambiente familiar (orrú, 2007.p.19). Tem como objetivo compreender a inclusão escolar na educação infantil, identificando práticas pedagógicas que facilitam a inclusão escolar das crianças autistas. A formação de professores necessita cada vez mais de novos conhecimentos para que esses possam trabalhar de maneira adequada $\mathrm{e}$ desenvolver um ensino de qualidade para esses alunos autista.

Neste trabalho aborda alguns teóricos e suas ideias, levando a conhecer sobre o autismo.

Segundo orrú (2007), em 1949, kanner referiu o quadro do autismo como "autismo infantil precoce", devido à dificuldade da relação com o contato com os outros indivíduos e seu acentuado por determinados objetos e coisas, suas alterações na fala, impedindo a Comunicação interpessoal.

Foi em 1954 que karnner frisou o "autismo infantil como psicose e continuo nessa linha até o final de seus trabalhos. Karnner identificou o autismo apenas em indivíduos que não sofriam com retardo mental, porem encontrou em indivíduos com retardo mental o quadro autístico e varia muito de pessoas para pessoas. Então, acreditava-se que o retardo mental era uma das características do autismo.

Atualmente, sabe-se que o retardo mental não é uma característica da síndrome autista. Entretanto, uma grande porcentagem de pessoas com autismo pode apresentar retorno mental como característica associada. Muitas vezes, por desconhecimento ou falta de olho clinico, ocorre uma confusão entre retardo mental e autismo (Goméz; terán, 2014, p.450.

De acordo com arrú (2007), em 1955, passou a se considerar a maneira de como os pais tratavam seus filhos e suas constantes mudanças de humor afetava a criança, levando ao desenvolvimento do autismo. 
Em 1968, kanner acrescento às suas contribuições a necessidade do diagnostico diferente com deficientes mentais e afásicos, fazendo uma revisão dos primeiros casos estudados por ele, propondo-me novas possibilidades fossem estudadas com auxílio da broquímicas, pontuando em 1973, a pertinência da síndrome como integrante das psicoses infantis orrú (2007)

As escolas recebemos alunos com necessidades especiais na tentativa de inclusão, não tendo as adaptações necessárias, essas crianças apresentam algumas dificuldades de aprendizagens, nesta perspectiva o atendimento educacional especializado para contribuição do trabalho oferecido na sala de aula, é importante que os professores tenham recursos multifuncionais para definirem estratégias pedagógicas.

O decreto $\mathrm{n}^{\mathrm{a}}$ 7.611, de 17 de novembro de 2011, retrata sobre educação especial o AEE, que disponibiliza determinadas providencias. No artigo $1^{\circ}$, destaca:

Para fins deste decreto, considera-se público-alvo da educação especial as pessoas com deficiência, com transtornos globais do desenvolvimento e com altas habilidades ou superdotação.

Os objetivos do atendimento educacional especializado são sobressaídos no art. $3^{\circ}$, eles são:

I - Prover condições de acesso, participação e aprendizagem no ensino regular e garantir serviços de apoio especializados de acordo com as necessidades individuais dos estudantes;

II- Garantir a transversalidade das ações da educação especial no ensino regular;

III- fomentar o Desenvolvimento de recurso de didáticos e pedagógicos que eliminem as barreiras no processo de ensino e aprendizagem;

IV- Assegurar condições para a continuidade de estudos nos demais níveis etapas e modalidades de ensino.

Existem poucos recursos instrumentais para realização do diagnóstico do indivíduo com suspeita de autismo e, mesmo com muitos estudos na área não existe nenhum marcador biológico que possibilite um exame preciso para confirmação ou não desse diagnóstico. Outro fator importante a ser salientado é a forma como ocorrera a comunicação do diagnóstico de autismo dos pais. É um processo delicado, que promove uma oportunidade única dos profissionais em estabelecerem uma aliança de confiança com eles, e para que possam elaborar o diagnóstico de forma mais coerente possível e menos estressante (bosa; semensato, 2013).

Cabe aos pais compreender, portanto, as reais necessidades do seu filho e aceitar principalmente suas diferenças, para que possam deixar de lado o medo de serem inadequados, buscando auxilio e informação a respeito da sua condição.

\section{A reabilitação é um processo dinâmico e global orientado para a recuperação física e psicológico do indivíduo com deficiência, tendo como objetivo a sua reintegração social. (batista, 2012, p.3).}

Em 2013, o ministério da saúde brasileira em parceria com o sistema único de saúde (sus), criam uma cartilha denominada "diretrizes de atenção à reabilitação da pessoa com transtorno do espectro do autismo (TEA). Essas diretrizes tem como objetivos central salientar as orientações às equipes multiprofissionais para o cuidado à saúde do indivíduo com TEA e as família, nos diferentes pontos de 
atenção de cuidados a pessoa com deficiência. Para as elaborações, foram utilizados o código internacional de funcionalidade de funcionalidade e capacidade (CIF) e os sistemas internacionais de classificação estatística internacional de doenças e problemas relacionadas a saúde (CID-10) (MINISTERIO DA SAÚDE, 2013).

A psicoterapia tem como objetivo auxiliar a interpretar a linguagem corporal, a comunicação não verbal, a aprendizagem e as interações sociais. Para contribuição do ensinamento dos autistas.

Síndrome do autismo diante de uma criança com dificuldade para aprender e não com uma impossibilidade, sendo assim todos os recursos facilitários devem ser empegados na inclusão dessas crianças. Atualmente no Brasil vários eventos são realizados a fim de desmistificar e esclarecer vários pontos relacionados a essa síndrome, exemplo a criação do dia da conscientização do autismo (dois de abril) e as leis Berenice Piana segundo a qual os portadores do autismo devem ser considerados deficientes, para fins legais isso foi um verdadeiro marco na conscientização da síndrome. É fundamental que haja uma preparação da sociedade para receber e aceitar os autistas e com isso exercitar a cidadania, pois isso só e possível quando manifestamos esforços para entender, tolerar e não discriminar.

A inclusão do aluno autista em escola regular passa necessariamente pela presença do mediador escolar que são profissionais devidamente habilitados para promover a saúde e a interação entre todos os alunos. Quando a convivência com o deficiente se transformar em um habito rotineiro e feito sem alardes, a sociedade será de fato inclusiva. A criança autista necessita aprender regras sociais, o que chamamos de "currículo oculto".

Segundo dados da ONU,1\% da população mundial (um em cada 68 indivíduos) apresenta algum transtorno do espectro do autismo, sendo mais comum em meninos do que em meninas (no caso da síndrome de asperger, especialmente) e ocorrem independente de questões de etnia, localização geográfica ou condições econômicas. Devido ao conhecimento de suas causas, tratamentos preventivos ainda não são oferecidos, mas há um consenso em afirmar que precisa ser detectado e tratado o quanto antes com rotinas e terapias especificas para cada criança e grau de comprometimento. Além dos profissionais de saúde envolvidos (pediatras, psicólogos, fonoaudiólogos e terapeutas ocupacionais) os profissionais da educação também fazem parte desse processo.

O transtorno do espectro autista (TEA) é classificado em três graus: autismo leve, moderado e severo. Etimologicamente falando, autismo vem da palavra de origem grega "autos" cujo significado é "próprio ou de si mesmo", sendo caracterizado como um distúrbio neurológico que surge ainda na infância causando atrasos no desenvolvimento na aprendizagem.

Não existe uma diretriz clara de como trabalhar com crianças autistas na educação, afinal, cada sujeito expressa de forma diferente o transtorno e deve ser olhado na sua subjetividade e na relação com os outros. A socialização é uma ferramenta essencial para uma boa aprendizagem dos alunos. Estabelecer vínculos amigáveis e confiáveis, diferentes afetos e ter uma base solida de relações é um dos pilares que sustentam a educação enquanto formação humana, a socialização é um processo imprescindível para qualquer 
aluno, o professor deve escutar o que o aluno e a família têm a dizer sobre a forma que ele estabelece suas relações sociais, auxiliando - o e apoiando para fortalecer no seu processo educativo.

A inclusão de uma criança autista na escola, para isso é fundamental que todos os envolvidos, família, amigos e escola, os tratem normalmente, tentando entendê-los na sua forma de ser, proporcionando tratamento em todas as áreas que precisem. Toda criança portadora e quaisquer necessidades especiais tem direito a educação que necessita, o importante é compreender que ela é uma criança que precisa ser amada acima de tudo, para ajudar uma criança autista deve-se buscar informações sobre autismo

Para mittler (2003), o objetivo da inclusão é de garantir que todas as crianças possam fazer parte de um grupo, de uma comunidade e de um sistema educacional que possa oferecer-lhes as mesmas oportunidades que crianças que não possuem necessidades especiais, numa tentativa de impedir que minorias sócias, na qual se incluem crianças portadoras da síndrome autista, escapem do preconceito e do isolamento. $\mathrm{O}$ ato aponta que as escolas possuem limites no que diz respeito ao que oferecer a estes alunos incluídos e reflete sobre a necessidade de mudanças nas políticas educacionais vigentes nos países que adotaram ou que irão adotar o processo de inclusão social como parte do sistema de educação das escolas, sabendo que a inclusão escolar é um modelo mundial apoiada pela organização das nações unidas (ONU).

\section{DESENVOLVIMENTO}

\section{1- Autismo na educação infantil.}

Criada por Eugene Bleuler, em 1911 a palavra autismo "é um sintoma da esquizofrenia, traços da psicose, os primeiros estudos sobre o autismo deram início em 1943, pelo psiquiatra americano Leo kanner quando descreve por meio de um artigo, um estudo baseado em11 crianças que apresentavam característica individualizadas em relação às demais síndrome. Kanner nomeou inicialmente como distúrbio físico". Analisado no comportamento um "afastamento social" desde o nascimento. Também observou alguns sintomas que surgem.

Kanner em 1949, refere-se ao quadro como nome de autismo infantil précoze, evidenciado sérias dificuldades de contatos com pessoas, ideia fixa em manter os objetos e as situações sem varia-las, fisionomia inteligente, alterações na linguagem do tipo inversão pronominal, neologismo e metáforas (Rodrigues, 2010, p.18).

Os sintomas do autismo eram primários kanner identificou, e diversas psicoses infantis como a esquizofrenia infantil. Outros pesquisadores desenvolveram estudos na concepção de kanner relacionado ao autismo a um déficit cognitivo e social, considerando um distúrbio do desenvolvimento.

O autismo é definido pela organização mundial de saúde como um distúrbio do desenvolvimento, sem cura e severamente incapacitante. Sua incidência é de cinco casos em cada 10.000 nascimentos caso se adote um critério de classificação rigorosa, e três vezes maior se considerar casos correlatados, isto é, que necessitem do mesmo tipo de atendimento (mantoon, 1997, p.13).

O autismo aparece em geral nos três primeiros anos de vida, a que é uma síndrome por apresentar agrupamento de sintomas envolvendo três áreas básicas, o comportamento, a interação social, e comunicação. Também podem apresentar habilidades motoras, musicais e outras. 
Jeapiaget (2007) estudioso do desenvolvimento cognitivo, afirma que o indivíduo é ativo no processo de aprendizagem estabelecendo se conhecimento através das suas ações, mesmo não sucede com as crianças autistas, é uma forma diferente e não padronizada o seu desenvolvimento.

$\mathrm{Na}$ escola apresenta diferentes grupos sociais em sala de aula, o aluno terá conhecimento nas suas experiências vivenciadas a apresentação do professor é algo destacado, que não são capacitados para trabalhadores com crianças autistas.

A declaração de Salamanca afirma:

As competências necessárias para satisfazer as necessidades educativas especiais devem ser ditas em consideração na avaliação dos estudos e na cerificação dos professores [...] a formação em serviço devera realiza-se sempre que possível, ao nível da escola, através da interação com os orientadores e apoiados pela formação a distância e outros forma de auto formação (1994, p.27-28).

Algumas escolas realizam capacitações dos educadores, é importante que os professores aprendam novos métodos para serem trabalhados para serem crianças autistas desenvolver mais. Após a constituição de 1988 a educação passou a ser um direito de todas as crianças, tendo o acesso à educação e exercendo a sua cidadania, sendo assim, a LDB (lei de diretrizes e bases da educação nacional). Vem assegurando que a educação infantil, segundo os artigos 29 e 30 da referida lei: é lei que professores incluam os alunos, mas é evidente que encontrará desafios para inserir o aluno autista na sala de aula, muitos professores não tem formação adequada para trabalhar com crianças autistas. As dificuldades podem ser encontradas pelo professor e a linguagem do aluno, tendo

Dúvidas em relação as práticas pedagógicas ou falta de recursos para proporcionar uma aprendizagem eficaz.

De acordo com mantoon:

A escola para se torna inclusiva, deve
acolher todos os seus alunos,
independentemente de suas condições
sócia, emocionais, físicas,
intelectuais, linguísticas entre outros.
Ela deve ter como princípio básico
desenvolver uma pedagogia capaz de
educar e incluir todos aqueles com
necessidades educacionais especiais e
também os que apresentam
dificuldades temporárias ou
permanentes, pois a inclusão não se
aplica apenas aos alunos que
apresentam algum tipo de deficiência
(mantoon, 2008, p..143).

A inclusão deve ser aplicada no currículo escola para aluno com alguma deficiência pois todos tem direito a inclusão. O professor deve estar disposto para trabalhar com qualquer aluno que tenha alguma dificuldade, sua pratica deve está adequada e preparada, buscando especializações e novos conhecimentos para trabalhar com alunos autistas.

Em 1996, a lei de diretrizes e bases da educação nacional (LDBBEN), lei $\mathrm{n}^{\circ}$ 9.394/96 reorganiza a concepção do ensino voltada a pessoa com necessidades educacional especial e estabelece um sistema de ensino e que valente a uma educação inclusiva. No capítulo $\mathrm{V}$, da sessão da educação especial, em seu art.59 expõe que os sistemas de ensino assegurarão aos educandos com necessidades educacionais especiais:

Currículo, métodos, técnicas, recursos educativos e organização, especificas para atender as suas necessidades; 
termina idade especificas para aqueles que não puderem atingir o nível exigido para a conclusão do ensino fundamental, em virtude de sua deficiência [...], professores com especialização adequada, em nível médio para a conclusão do trabalho, desenvolve estudo teórico, uma metodologia qualitativa ou superior, para atendimento especializado, bem como professores do ensino regular capacitados para a integração desses educandos nas classes comuns; educação especial para o trabalho, visando a sua efetiva integração na vida em sociedade, inclusive condições adequadas para os que não revelarem capacidade de inserção no trabalho competitivo, mediante articulação com o órgão oficiais afins [...] acesso e qualitório aos benefícios aos programas sociais suplementares disponíveis para o respectivo nível do ensino regular(Brasil,1996,p.19-20).

A inclusão para o processo de reconhecimento de qualquer necessidade educacional especial (NEE), mesmo a lei orientando as possibilidades de inclusão nos dias atuais, há uma luta constante para que sejam fortalecidas essas práticas inclusivas. As diretrizes nacionais da educação inclusiva (2001) relimam visões estabelecidas pela sociedade.

\section{CONSIDERAÇÕES FINAIS}

O trabalho escolar inclusivo não deve foca-se nas dificuldades apresentadas pelo aluno autista, e em suas potencialidades proporcionando o trabalho do seu desenvolvimento. A relação família e escolar é muito importante para um trabalho inclusivo, a comunicação entre família e escola contribui no processo social dentro desses ambientes.

A inclusão é um processo continuo, sendo que envolve família, escola e comunidade escolar. E preciso estar atento para a efetivação que a mesma propõe com uma escola inclusiva para o aluno autista não seja prejudicado. E necessário criar maneiras para transmitir novas informações e melhorar a pratica pedagógica em sala de aula. A falta de recursos didáticos, e o apoio nos ambientes educacionais dificulta as aprendizagens dos alunos autistas pois a inclusão não é apenas colocar o aluno na sala de aula, mas adapta-lo no contexto escolar para construir um conhecimento da maneira própria da criança.

Entende-se que quanto mais cedo a criança for diagnosticada e inicia $o$ tratamento, maiores serão as possibilidades de desenvolvimento dentro das suas capacidades físicas e mentais, assim como qualquer indivíduo, o autista é o único dentro de sua singularidade. Para a conclusão doo trabalho, desenvolve estudo teórico, uma metodologia qualitativa. Por fim, conclui-se que os alunos e famílias são fundamentais para o avanço destes alunos.

\section{OBJETIVOS ESPECÍFICOS}

Desenvolver estudos bibliográfico sobre o tema, contribuindo com o desenvolvimento ensino aprendizagem.

Contribuir para o desenvolvimento das abordagens metodológicas com os alunos autista.

\section{REFERÊNCIAS BIBLIOGRÁFICAS}

ARRÚ, S. E. Autismo; linguagem e educação: interação social no cotidiano escolar. Rio de janeiro: wak editora. 2007

BRASIL. DECRETO N ${ }^{\mathrm{a}} 77.611$, de 17 de novembro de 2011 Brasília, 2011.

\section{BOSA, CLEONICE ALVES}

SEMENSATO, Marcia reané. A família de crianças com autismo: contribuições clinicas e empíricas. Autismo, educação e 
transdisciplinar idade. 2.ed. campinas:

papiros, 2013

BRASIL. MINISTERIO DA SAUDE, secretaria de atenção à saúde. Diretrizes de atenção da pessoa com transtornos dos espectros do autismo (TEA), BRASILA, 2013.

BOTISTA, CRISTINA Abranches mota. Deficiência, autismo e. psicanálise. Revista ciências psicologia, V.04 N 02, 2012.

BRASIL, ministério da educação.

Diretrizes nacionais para a educação especial na educação básica/ secretaria de educação especial MEC; SEESP,2001.

BRASIL, lei $\mathrm{n}^{\mathrm{a}}$ 9.394, de 20 de dezembro de 1996. Estabelece as diretrizes e bases da educação, brasileira, DF,1996.

DECLARACAO DE SOLAMANCA.

Necessidades educativas especiais -NEE UNESCO 19994.

GÓMEZ, A.M.S, terán, N.E transtornos de aprendizagem e autismo. Cultural, S.A.

2004

MITTLER, P. (2003). Educação inclusiva. Contextos sociais. Porto alegre: Artmed.

MONTOAN, MARIA TEREZA eglér. A integração de pessoas com deficiência. São Paulo: memnon, 1997.

MONTOAN, MARIA EREZA.E. Inclusão social: o que é? Porquê? Como fazer? Ed. moderna, são Paulo 2008. 